\title{
NETosis and thrombosis in vaccine-induced immune thrombotic thrombocytopenia
}

Beng Chong ( $\sim$ beng.chong@unsw.edu.au )

University of New South Wales

\section{Halina Leung}

University of New South Wales

Jose Perdomo

University of New South Wales

Zohra Ahmadi

University of New South Wales

Fairooj Rashid

University of Sydney

Anoop Enjeti

Calvary Mater Hospital

Stephen Ting

Monash University https://orcid.org/0000-0001-7755-8326

James Chong

Westmead Institute for Medical Research https://orcid.org/0000-0002-5201-4856

\section{Article}

Keywords: adenoviral vector vaccines, COVID-19, neutrophil extracellular traps

Posted Date: September 30th, 2021

DOl: https://doi.org/10.21203/rs.3.rs-753825/v1

License: (c) (1) This work is licensed under a Creative Commons Attribution 4.0 International License.

Read Full License

Version of Record: A version of this preprint was published at Nature Communications on September 5th, 2022. See the published version at https://doi.org/10.1038/s41467-022-32946-1. 


\section{NETosis and thrombosis in vaccine-induced immune thrombotic thrombocytopenia}

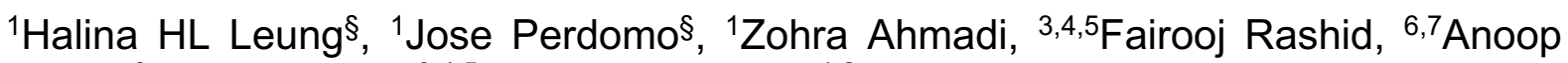
Enjeti, ${ }^{8}$ Stephen Ting, ${ }^{3,4,5}$ James JH Chong, ${ }^{1,2}$ Beng H Chong*

${ }^{1}$ Haematology Research Unit, St George and Sutherland Clinical School, University of New South Wales, Sydney, Australia; ${ }^{2}$ New South Wales Health Pathology, Sydney, Australia; ${ }^{3}$ Department of Cardiology, Westmead Hospital, Sydney, Australia; ${ }^{4}$ Sydney Medical School, Faculty of Medicine and Health and ${ }^{5}$ Centre for Heart Research, Westmead Institute for Medical Research, University of Sydney, Australia; ${ }^{6}$ Calvary Mater Hospital, Wallsend, New South Wales, Australia; ${ }^{7}$ University of Newcastle, Callaghan, New South Wales, Australia; ${ }^{8}$ Eastern Health and Monash University, Melbourne, Victoria, Australia

§These authors contributed equally to the study

Abstract: 253 words

Text: 2300 words

Methods: 1232 words

Figures: 4

Extended Data Figures: 2

Corresponding author:

Beng $\mathrm{H}$ Chong,

New South Wales Health Pathology and St George and Sutherland Clinical School, University of New South Wales,

Gray Street, Kogarah, NSW 2217, Australia

Tel +61291133426 Fax +61291133942

47 Email: beng.chong@unsw.edu.au 


\begin{abstract}
Vaccine-induced immune thrombotic thrombocytopenia (VITT) is a rare yet serious adverse effect of adenoviral vector vaccines (AstraZeneca and Johnson \& Johnson) against COVID-19 ${ }^{1}$. Anti-platelet factor 4 (PF4) antibodies are present in VITT patients $^{2,3}$. Although the current view suggests that platelet activation by anti-PF4 antibodies is the cause of thrombosis there is as yet no direct evidence that the antibodies induce clot formation and thrombocytopenia (reduction in platelet counts) in VITT and the mechanisms involved remain unknown ${ }^{4}$. Here we show that VITT antibodies induce thrombosis and thrombocytopenia, and that thrombus formation is mediated by neutrophil extracellular traps (NETs). We found markers of NETosis, abundance of neutrophil/platelet aggregates and presence of neutrophils undergoing NETosis in patients with active VITT. VITT antibodies directly stimulate neutrophils to release NETs and induce thrombus formation containing abundant platelets, neutrophils, fibrin, extracellular DNA and citrullinated histone $\mathrm{H} 3$ using an in vitro blood flow microfluidic system. In transgenic mice expressing human PF4 and Fc $\gamma$ RIla, VITT antibodies lead to thrombosis, thrombocytopenia and formation of low density granulocytes. Pharmacological and genetic inhibition of NETosis prevents VITTinduced thrombosis in mice but not thrombocytopenia. In contrast, in vivo blockage of Fc $\gamma$ RIla abrogates both thrombosis and thrombocytopenia suggesting they are distinct processes. Our findings indicate that VITT antibodies activate cells via Fc $\gamma$ RIla and are responsible for thrombosis and thrombocytopenia. This study identifies NETosis as a pathogenic mechanism for thrombus formation in VITT. We anticipate our findings will motivate future development of NETosis and FcyRIla inhibitors as potential specific therapies for VITT and consequently better patient outcomes.
\end{abstract}


Vaccine-induced immune thrombotic thrombocytopenia (VITT), also known as thrombosis with thrombocytopenia syndrome (TTS), is an uncommon but serious adverse effect of adenoviral vector-based SARS-CoV-2 (COVID-19) vaccines, specifically ChAdOx1 nCoV-19 (Vaxzevria, AstraZeneca) and Ad26.COV2.S (Johnson \& Johnson) ${ }^{1,5}$. VITT resembles heparin-induced thrombocytopenia (HIT) which is an immune reaction to a commonly used anticoagulant drug, heparin ${ }^{6}$. Like patients with HIT, patients with VITT present with thrombocytopenia (low platelets) and thrombosis (blood clots, often at unusual sites) and have an anti-platelet factor 4 (PF4) antibody which induces platelet activation ${ }^{4}$. The high mortality of VITT (fatality rate estimated at $23 \%{ }^{3}$ to $40 \%{ }^{4}$ ) has caused serious concerns among physicians, public health officials and the public, leading to vaccine hesitancy undermining vaccine rollout in many countries. This is exacerbated by the lack of knowledge of its underlying disease mechanism.

It is generally believed that platelet activation by the anti-PF4 antibody causes thrombosis in VITT despite the lack of scientific evidence of this antibody inducing clot formation either in vitro or in vivo. Besides, this antibody is also present in individuals without thrombosis ${ }^{7}$. Experts have suggested that there is a need to show in vivo thrombus formation by the anti-PF4 antibody in a VITT animal model ${ }^{4}$ and also to understand the mechanism that causes thrombosis.

In HIT, we have previously shown that thrombosis is driven by NETosis ${ }^{8,9}$. Upon activation by pathogens, immune complexes and other stimuli, neutrophils release their granules and decondensed chromatin in the form of a DNA network, termed Neutrophil Extracellular Traps (NETs). NETs have two characteristic components, myeloperoxidase and citrullinated histone $\mathrm{H} 3(\mathrm{CitH} 3)$ which are often used as markers of NETs formation. NETosis is the process by which NETs are formed. NETs serve as a framework for thrombus formation and are highly thrombogenic - they activate platelets and other immune cells, damage endothelial cells ${ }^{10}$ and activate blood coagulation pathways ${ }^{11}$. NETosis is known to promote venous and arterial thrombosis ${ }^{12,13}$.

In this report, using a microfluidics blood flow assay we showed that the anti-PF4 antibody (purified IgG from patients with VITT) when added to circulating normal whole blood induced blood clot formation in vitro and when administered into FcyRIla $/ \mathrm{hPF}^{+}$ transgenic mice (a VITT animal model) induced thrombosis in vivo. We also demonstrated that the antibody-induced thrombosis was mediated by platelet and neutrophil activation and NETosis.

\section{Results}

\section{VITT patients}

VITT patients $(n=7)$ from five hospitals in Australia participated in the study. Mean age was 62 years (range: 44 - 82 years), 3 were female. Their clinical features and laboratory test results are consistent with those of previously reported cases of VITT $^{2,3,5}$. All received their first dose of COVID-19 vaccine (Vaxzevria, AstraZeneca) 12 - 32 days (mean: 19 days) before their admission to the hospitals, blood samples were collected soon after. All had thrombocytopenia (mean platelet count at admission: $58 \times 10^{9} / \mathrm{L}$, range: $8-128 \times 10^{9} / \mathrm{L}$ ) and thrombosis (cerebral venous sinus thrombosis, CVST: 2 patients, splanchnic vein thrombosis: 2, bilateral pulmonary 
thromboembolism and deep vein thrombosis: 3). All had elevated D-dimer levels, reduced or normal plasma fibrinogen, anti-PF4 antibodies detected by enzyme-linked immunosorbent (Fig. 1a) and positive for platelet activation functional assays (Fig. 1b, c).

\section{NETosis in VITT}

We next investigated the presence of markers of NETosis in VITT patients' plasma and whole blood from patients with active VITT. We assessed both the presence of citrullinated histone $\mathrm{H} 3(\mathrm{CitH} 3)^{14}$ and the concentration of cell free DNA (cfDNA) in plasma. The levels of $\mathrm{CitH} 3$ and cfDNA were significantly increased relative to healthy controls (Fig. 1d, e), which is consistent with the presence of NETosis ${ }^{9,15}$. Moreover, analysis of fresh blood from patients with active VITT showed the presence of abundant activated neutrophils (low density granulocytes or LDG) (Fig. 1f), neutrophilplatelet aggregates (NPA) (Fig. 1g, h) and neutrophils undergoing NETosis (Fig. 1i, j). Overall, this suggests that NETosis is present in patients with active VITT.

\section{VITT IgG induces NETosis in vitro}

Pathogenic anti-PF4 antibodies bind to endogenous PF4 and form immune complexes $^{16}$. These complexes interact with Fc $\gamma$ RIla to activate platelets and neutrophils ${ }^{9,16}$. To determine the effect of VITT antibodies in thrombosis, we first isolated total IgG from VITT patients' plasma and assessed its impact on whole blood from healthy donors. Compared to buffer (PBS) and normal IgG (Ctrl), incubation with VITT IgG led to a pronounced increase in the formation of LDG (Fig. 2a) and induction of neutrophils to undergo NETosis $\left(\mathrm{CD} 15^{+} \mathrm{CitH}^{+} \mathrm{MPO}^{+}\right.$cells) (Fig. 2b). By comparison, a HIT antibody, known to induce NETosis ${ }^{9}$, stimulated neutrophils to a comparable level (Fig. 2a, b). NETs induction in the absence of other cells was corroborated by treatment of purified neutrophils in the presence of PF4 with VITT or normal IgG and assessment of DNA release with the cell impermeant dye Sytox green. Significantly increased DNA release was triggered by VITT IgG relative to normal IgG (Fig 2c, d), indicating that purified IgG from VITT patients strongly initiated NETs formation in healthy donors' whole blood and purified neutrophils in vitro.

\section{VITT IgG induces thrombosis in vitro}

To examine the capacity of VITT antibodies to induce thrombosis, fresh whole blood from healthy donors were treated with VITT IgG or normal IgG and flowed through von Willebrand factor ( $\mathrm{vWf}$ )-coated microchannels in a microfluidics system. The presence of VITT IgG led to thrombus formation. Confocal microscopy imaging of thrombi formed following treatment with VITT IgG showed that the thrombi were formed by platelets, neutrophils and extracellular DNA, while no clots were formed in blood treated with control IgG (Extended data Fig. 1a, b). Further analysis of VITT IgGinduced thrombi showed an abundance of fibrin (Fig. 2e) and CitH3 (Fig. 2f) confirming the strong thrombogenic activity of VITT antibodies and their ability to induce NETosis in vitro. To confirm the role of Fc $\gamma$ RIla and NETosis in VITT-induced thrombosis, blood was pre-treated with anti-FcyRlla monoclonal antibody, IV.3 or DNase I prior to incubation with VITT IgG. The presence of IV.3 strongly inhibited deposition of platelets (Fig. $2 g, i$ ) and neutrophils (Fig. $2 g$, j). Furthermore, there was no induction of NETosis as indicated by the absence of DNA release in the presence of IV.3 (Fig. $2 \mathrm{~g}, \mathrm{~h})$. Similarly, the presence of DNase I resulted in inhibition of thrombus formation (Fig. 2g-j). These data suggest that direct blocking of FcyRlla inhibits NETosis and 
thrombosis, and digestion of extracellular DNA also inhibits thrombus formation in vitro.

\section{VITT IgG induces thrombosis in vivo}

To assess whether anti-PF4 antibodies are responsible for the clinical features of thrombocytopenia and thrombosis in VITT patients, we used a Fc $\gamma \mathrm{RIla}^{+} / \mathrm{hPF} 4^{+}$double transgenic mouse model. These mice are necessary to assess the activity of VITT IgG in vivo, since they express two essential components, human PF4 and Fc $\gamma$ RIla on platelets and neutrophils. VITT IgG was administered into the VITT mouse model and lungs extracted to examine the levels of thrombosis. Examination of extracted lungs (Fig. 3a, Extended Data Fig. 1c) from VITT IgG-treated mice showed extensive thrombi deposition in this organ. Thrombi were absent in control IgG treated animals (Fig 3a, Extended Data Fig. 1c). These clots contain abundant platelets, neutrophils (Fig. 3) and fibrin (Fig. 3c). These data suggest that VITT IgG is responsible for thrombosis in vivo.

\section{Role of Fc $\gamma$ RIla and NETosis in thrombosis in vivo}

To investigate the role of FcyRlla and neutrophil activation and NETosis in VITT IgGinduced thrombosis, inhibitors of FcyRIla (aglycosylated IV. $3^{9}$, agIV.3) and NETosis $(\text { GSK484) })^{9,17}$ were administered in vivo. In support of our in vitro findings (Fig. 2) blocking either FcyRlla or NETosis was effective in preventing the formation of clots in vivo as shown by the lack of clots (platelet and neutrophil accumulation) in lung sections of mice treated with agIV.3 (Fig. 3c). The dramatic reduction in thrombus deposition is also confirmed using whole organ imaging (Fig. $4 \mathrm{a}$, b) and quantitative analysis of platelet accumulation in mice treated with VITT IgG plus agIV.3 or GSK484 compared to mice treated with VITT IgG without either inhibitor (Fig. 4a, b). Moreover, inhibitor-treated mice were not only protected from thrombosis but also had significantly less low density granulocytes present in peripheral blood compared to control mice (Extended Data Fig. 1d).

The contribution of NETosis to thrombosis in VITT was further assessed using the VITT mouse model deficient in PAD4 (FcyRlla $/$ hPF4$\left.^{+} / \mathrm{PAD}^{-/-}\right)$. PAD4 is the enzyme responsible for the citrullination of histones necessary for induction of NETosis ${ }^{18}$. Consistent with findings in animals treated with VITT IgG plus GSK484, mice lacking PAD4 treated with VITT IgG had a dramatic reduction in clot formation compared to control VITT mice (which are wild type for PAD4) (Fig. 3c, Fig. 4a, b). There were also significantly fewer circulating low density granulocytes in PAD4 deficient mice compared to control (Extended Data Fig. 1d). Collectively, our data indicate that inhibition of platelet and neutrophil activation by blocking FcyRlla or inhibition of NETosis can efficiently abolish VITT IgG-induced thrombosis in vivo.

\section{VITT IgG induces thrombocytopenia in VITT mouse model}

Unlike mice treated with normal IgG, mice treated with VITT IgG experienced thrombocytopenia (Fig. 4c, d) and systemic reactions such as hypothermia (Extended Data Fig. 2a). AgIV.3 was effective in preventing both thrombocytopenia (Fig. 4d) and thrombosis (Fig. 3c, Fig. 4a). In contrast, NETosis inhibitor GSK484 and PAD4 knockout had no effect on the development of thrombocytopenia (Fig. 4e) although they strongly inhibited thrombosis (Fig. 4a, b). Altogether, these results indicate that VITT IgG-induced thrombosis and thrombocytopenia are distinct processes. 


\section{Discussion}

Although vaccines against COVID-19 infection have been very effective, there have been some serious side-effects. One of these is a rare clotting disorder termed VITT or TTS that has caused significant morbidity and mortality. It has generated much public concern globally resulting in vaccine hesistancy and undermining of vaccine roll-out in many jurisdictions.

Despite numerous recent publications ${ }^{1,19-21}$, there are still significant knowledge gaps in VITT, in particular regarding its underlying disease mechanism(s) ${ }^{4}$. There is yet no direct evidence that VITT antibodies cause thrombosis and thrombocytopenia in vivo. Better knowledge of VITT will improve public confidence which might contribute to increased vaccine uptake. The conventional concept is that the platelet activating antiPF4 antibody causes clot formation in VITT despite no direct evidence. The presence of anti-PF4 antibodies in individuals without thrombosis ${ }^{7}$ has created doubts about this concept.

\section{Evidence that anti-PF4 antibody induces clot formation}

Here we provide evidence that VITT antibodies directly induce thrombus formation in vitro and in vivo, not by platelet activation alone but also through neutrophil activation and NETosis.

In this study, we demonstrated that VITT IgG stimulated platelet activation via serotonin release and platelet aggregation assays as had other investigators previously ${ }^{22}$. More importantly, we further showed that VITT IgG when added in vitro to circulating whole blood induced clot formation in the microchannels using a microfluidics system. In contrast, normal IgG failed to induce thrombosis. Similarly, administration of VITT IgG but not normal lgG led to development of multiple thrombi in the lungs of the VITT mouse model (FcyRlla ${ }^{+} / \mathrm{hPF}^{+}$double transgenic mice). These data provide direct evidence that VITT IgG (or more specifically immune complexes formed by VITT IgG and PF4) induced clot formation in vitro and in vivo, filling a crucial knowledge gap in VITT pathogenesis. Thrombosis was blocked by anti-FcyRlla monoclonal antibody, IV.3 suggesting that it was mediated by Fc $\gamma$ RIla receptors on platelets and neutrophils.

\section{NETosis is a critical driver of thrombosis in VITT}

Our study and the study by Holm et $\mathrm{al}^{21}$ both showed the presence of NETosis in patients with VITT. In the latter study, NETosis markers occurred together with numerous markers of inflammation, activated innate immune pathways, activated blood cells and endothelium, and damaged tissues in VITT patients. These markers were present in the blood, in a thrombus and in the immune precipitates extracted by a goat anti-human PF4 antibody from plasma of VITT patients. These findings were not unexpected as the VITT patients had robust immune responses, intense inflammation and severe thromboses. However, there was no data implicating NETosis as the cause of thrombosis in the VITT patients. Even the presence of neutrophils and NETosis markers in the thrombus does not necessary indicate that it is the cause of thrombosis as neutrophils and NETs are frequently observed in thrombi in various conditions including stroke, acute myocardial infarction ${ }^{23,24}$ and deep vein thrombosis ${ }^{25}$. The authors, in fact, speculated in their report whether the adenovirus in the vaccine or even the spike protein could have triggered the pronounced inflammatory processes including NETosis. 
In contrast, our study not only provides evidence of the presence of NETosis in VITT, but we also show that NETosis directly drives thrombosis in VITT in vivo in the VITT animal model. Administration of VITT IgG but not normal IgG induced development of multiple thrombi in the lungs of the mice. Thrombosis could be prevented or substantially suppressed by administration of NETosis inhibitor, GSK484 or by using PAD4 knock-out mice (which blocks NETosis).

\section{VITT IgG induces thrombocytopenia}

We demonstrated here that VITT antibodies induced thrombocytopenia (platelet count decrease) in the VITT mouse model by binding to platelet Fc $\gamma$ RIla. Thrombocytopenia was substantially prevented by anti-Fc $\gamma$ RIla monoclonal antibody, IV.3. In contrast, NETosis inhibitor GSK484 and absence of PAD4 (Fc $\gamma \mathrm{RIla}^{+} / \mathrm{hPF} 4^{+} / \mathrm{PAD} 4^{-/-}$mice) which significantly blocked thrombosis in VITT had no effect on thrombocytopenia, suggesting that thrombosis and thrombocytopenia in VITT are two distinct processes as we have previously shown in heparin-induced thrombocytopenia ${ }^{9}$.

In summary, our findings showed that anti-PF4 antibodies are the pathogenic or disease-causing antibodies in VITT. They induce platelet and neutrophil activation leading to development of NETosis which is the major driver of thrombosis in VITT (Extended Data Fig. 2b). FcyRIIA blockage prevented both thrombocytopenia and thrombosis but NETosis inhibition which effectively suppressed thrombosis, had no effect on thrombocytopenia. Thrombosis and thrombocytopenia appeared to be mediated by two distinct mechanisms.

Our results have contributed to a better understanding of pathogenesis in VITT and may also lead to development of disease biomarkers and improved diagnosis and new more efficacious therapies for VITT and consequently better clinical outcomes for the patients. 


\section{Methods}

\section{Human samples}

VITT samples were collected from patients in Australia from the following hospitals: St George Hospital, Kogarah, Sydney, New South Wales; Calvary Mater Hospital, Wallsend, New South Wales; Box Hill Hospital, Box Hill, Victoria; University Hospital Geelong, Geelong, Victoria and Townsville University Hospital, Townsville, Queensland. Blood was collected from patients clinically diagnosed with HIT and VITT and positive for laboratory tests (ELISA and serotonin release assay) ${ }^{5,26}$. Blood from healthy donors was used in control experiments. This study was approved by the Human Research Ethics Committee of South Eastern Sydney Local Health District (17/211 LNR/17/POWH/501). Informed consent was obtained from all study participants. Sera and plasma samples were stored in aliquots at $-80^{\circ} \mathrm{C}$ until required for analysis.

\section{Diagnostic assays}

The abundance of anti-PF4 or anti-PF4/heparin antibodies in patient sera was measured using a solid phase PF4 or PF4/heparin ELISA performed in microwell plates. Sera from patients or healthy donors were added to each well and incubated for $60 \mathrm{~min}$ at room temperature and then washed. Conjugated anti-human IgG was added, incubated for $60 \mathrm{~min}$ at room temperature and washed. Chromogenic substrate reaction was stopped with $1 \mathrm{M} \mathrm{H}_{2} \mathrm{SO}_{4}$. Optical density was measured using an automatic plate reader (Tecan Infinite Pro).

${ }^{14} \mathrm{C}$ serotonin-release assay $\left({ }^{14} \mathrm{C}-\mathrm{SRA}\right)$ was performed as previously described ${ }^{27}$. Briefly, washed donor platelets were incubated with radiolabelled ${ }^{14} \mathrm{C}$ and heat inactivated patient's sera, in the presence and absence of PF4 $(10 \mu \mathrm{g} / \mathrm{mL}), 0.1 \mathrm{U} / \mathrm{mL}$ heparin, IV.3 antibody $(50 \mu \mathrm{g} / \mathrm{mL})$ or $100 \mathrm{U} / \mathrm{mL}$ heparin, for $60 \mathrm{~min}$ at room temperature while stirring. Reaction was stopped using PBS-EDTA buffer and centrifuged. Radioactivity (counts per minute) of the supernatant was measured using a beta-counter. Levels greater than $20 \%$ were considered positive.

\section{Antibodies}

Purification of immunoglobulin $G$ antibodies from patients' or healthy donor's sera was performed using Protein G Agarose (Roche Mannheim, Germany). The AKTA purifier chromatography system (GE Healthcare) was used for purification. Eluted peak fractions were pooled and concentrated using ultracentrifugal units. Purity of IgG was $>95 \%$ as determined by SDS PAGE Gel analysis. Functional activity of purified IgG was determined by platelet aggregation and serotonin release assays. Hybridoma cells producing IV.3 were obtained from ATCC (clone HB-217). Cells were cultured in DMEM medium containing $10 \% \mathrm{FBS}$ at $37^{\circ} \mathrm{C}, 5 \% \mathrm{CO}_{2}$. Cells were cultured in serumfree DMEM $24 \mathrm{~h}$ prior to collection of antibody-containing supernatant. Protein $\mathrm{G}$ Sepharose affinity chromatography was used to purify IV.3.

\section{Platelet aggregation}

Light transmission platelet aggregometry was used to determine antibody activity and role of FcyRIla in VITT-induced platelet aggregation. Platelet-rich plasma (PRP) was prepared from citrate-anticoagulated healthy donor blood by centrifugation at room temperature at $150 \mathrm{~g}$ for $10 \mathrm{~min} .50 \mu \mathrm{L}$ of VITT or normal sera was added to a cuvette with $300 \mu \mathrm{L}$ of PRP with or without FcyRIla-inhibitor, IV.3 $(20 \mu \mathrm{g} / \mathrm{mL})$, whilst stirring at $37^{\circ} \mathrm{C}$ for $15 \mathrm{~min}$. Platelet poor plasma was used as blank. 


\section{Quantification of NETosis markers}

Cell-free DNA was measured in plasma of VITT and healthy donor samples using Quant-iT ${ }^{\mathrm{TM}}$ PicoGreen ${ }^{\mathrm{TM}}$ dsDNA assay kit (P11496, Invitrogen), as described by the manufacturer. Plasma levels of citrullinated histone $\mathrm{H} 3$ were determined using the H3R8Cit ELISA Capture and Detection kit (R\&D143002, EpiCypher) ${ }^{14}$ following the manufacturer's instructions.

\section{Cell isolation}

Neutrophils were purified using EDTA-anticoagulated blood and the EasySep Direct Human Neutrophil Isolation kit (19666, StemCell Technologies) following the manufacturer's instructions. Purified neutrophils are free of platelets and other blood cells as assessed by flow cytometry. Washed platelets were prepared from citrateanticoagulated blood. For low density granulocytes, whole blood was diluted with PBS and Lymphoprep (07851, StemCell Technologies) was gently underlayed to avoid mixing with the diluted blood. Sample was then centrifuged at $800 \times \mathrm{g}$ for $20 \mathrm{~min}$ at room temperature. Peripheral blood mononuclear cell layer was harvested.

\section{Flow cytometry}

Fresh citrate-anticoagulated blood from VITT patients or healthy donors was diluted with PBS. Platelet-neutrophil aggregates were analysed using anti-CD15 (Alexa Fluor 647, BD 562369) and anti-CD41a (PE, BD 555467), NETs were identified using anticitrullinated histone $\mathrm{H} 3$ (ab5103), anti-MPO (PE, BD 341642) and goat anti-rabbit IgG (BV421, BD 565014). Monocytes and low density granulocytes were identified using anti-CD14 (V500, BD 561391) and anti-CD15 (Alexa Fluor 647, BD 562369) or antiLy6G (V450, BD560603) and anti-CD11b (PE, BD 557397). Platelet counts in mouse blood were determined by number of events acquired in 60 s relative to time 0 . Flow cytometry data were analysed using FlowJo software (LCC, USA.

\section{Timelapse}

Purified neutrophils were stained with Hoechst 33342 (14533, Sigma) and seeded into eight-well Nunc Lab-Tek II chambers. Purified VITT IgG $(5 \mathrm{mg} / \mathrm{mL})$ or normal IgG (5 $\mathrm{mg} / \mathrm{mL})$ with PF4 $(12 \mu \mathrm{g} / \mathrm{mL})$ were added to each reaction. Release of extracellular DNA was measured using Sytox Green (S7020, Invitrogen). Wells were imaged using a confocal laser-scanning microscope (Leica TCS SP8). Sytox green fluorescence relative to Hoechst 33342 fluorescence was calculated with ImageJ software (version 2.1.0/1.53c, NIH).

\section{Microfluidics}

Citrate-anticoagulated blood was diluted 1:2 with PBS, supplemented with purified IgG (VITT IgG $3 \mathrm{mg} / \mathrm{mL}$, normal IgG $3 \mathrm{mg} / \mathrm{mL}$ ) and incubated at $37^{\circ} \mathrm{C}$ for $90 \mathrm{~min}$. In selected experiments, blood was pre-incubated with IV.3 $(20 \mu \mathrm{g} / \mathrm{mL})$ or DNase I (160 $\mathrm{U} / \mathrm{mL})$. Blood was stained with combinations of Hoechst $33342(3 \mu \mathrm{g} / \mathrm{ml})$, Sytox green $(0.3 \mu \mathrm{M})$, anti-CD41 Alexa $647(15 \mu \mathrm{g} / \mathrm{mL})$, anti-CD41-FITC $(15 \mu \mathrm{g} / \mathrm{mL})$, anti-CD15 Alexa $647(15 \mu \mathrm{g} / \mathrm{mL})$, anti-fibrin Alexa $594(30 \mu \mathrm{g} / \mathrm{mL})$, anti-CitH3 Alexa $594(30$ $\mu \mathrm{g} / \mathrm{mL}$ ) prior to perfusion through Vena8 Fluoro+ ${ }^{\mathrm{TM}}$ biochip microchannels coated with vWf (Haematologic Technologies United BioResearch Products Pty Ltd). Biochips were mounted on a fluorescent microscope (Zeiss Axio Observer.A1) and fluorescence images from different microscopic fields were captured in real time with a Q-Imaging EXi Blue ${ }^{\mathrm{TM}}$ camera (Q-Imaging, Surry, BC, Canada) with the fluid shear 
stress set at 67 dyne $/ \mathrm{cm}^{2}$ (shear rate 1500/s) for $30 \mathrm{~min}$. Selected samples were fixed with $2 \%$ paraformaldehyde and imaged by confocal microscopy.

\section{Mouse model}

Mice expressing the $\mathrm{R}^{131}$ isoform of human FcyRlla and human PF4 were generated in C57BL/6 background. Double transgenic (FcyRlla $\left.{ }^{+} / \mathrm{hPF}^{+}\right)$and $\mathrm{FcyRIIa}^{+} / \mathrm{hPF} 4^{+} / \mathrm{PAD}^{-/-}$have been characterised previously ${ }^{9,28}$. VITT was recreated in these mice by intravenous injection of purified VITT IgG $(250 \mu \mathrm{g} / \mathrm{g})$. Inhibitors of NETosis (GSK484, Cayman chemicals) or anti FcyRlla (aglycosylated IV.3, 1 mg/g) were injected at time 0. Anti-CD42c Dylight-649 antibody (Emfret, Germany) and Alexa Fluor 594-fibrinogen were used to label mouse platelets and fibrin in vivo, respectively. Following euthanasia, lungs were perfused with PBS followed by formalin, extracted and imaged using the IVIS Spectrum (Perkin Elmer). Fluorescence was calculated in radiant efficiency using living Image 4.5.5 software (Perkin Elmer). All animal experiments were approved by the University of New South Wales Animal Care and Ethics Committee.

\section{Histology}

Formalin-fixed lungs were embedded in paraffin, sectioned at 4 microns and mounted onto slides. Slides were deparaffinised, rehydrated, and underwent heat-induced antigen retrieval. Slides were probed with anti-Ly6G (Alexa Fluor 488, 127626 Biolegend). Vectashield antifade mounting medium with DAPI (H-1200, Vector Laboratories) was used to mount glass coverslips onto the slides. Slides were imaged by confocal microscopy. Slides were also stained with H\&E and imaged with a Zeiss Axioskop microscope.

\section{Statistical analyses}

Statistical tests were performed using GraphPad Prism version 8 (GraphPad Software, USA). The following statistical tests were used in this study as described in the figure legends: (1) Shapiro-Wilk normality test. (2) Student's t test was performed when comparing between two groups. (3) Multiple comparisons were analysed by one-way ANOVA with post-test correction for multiple comparisons. Each individual healthy donor for in vitro experiments and each mouse used for animal experiments was considered a biological replicate. $\mathrm{P}$ values $<0.05$ were considered statistically significant.

Acknowledgments: The authors wish to thank Steven McKenzie (Philadelphia, USA) for providing FcyRlla ${ }^{+} / \mathrm{hPF}^{+}$mice, Drs Feng Yan, Rose Wong and Kathryn Evans for valuable technical assistance, Drs Sumita Ratnasingam, John Cassey and Silvia Zheng for management of VITT patients and valuable clinical input, O Szeto, J Bennett, M Poxton, E Heyer and $P$ Rojanski for assistance in obtaining human research ethics/governance approvals, and members of the THANZ VITT Advisory Group for helpful discussion of VITT patients. This work was supported by grants from National Health and Medical Research Council, Australia, Program Grant APP1052616 and New South Wales Capacity Program Senior Researcher Grant RG201677 to BHC; NSW Health Cardiovascular Disease Clinician Scientist Grant and National Health and Medical Research Council Australia, Investigator Grant to JJHC 
1 Author contributions: BHC conceived the idea, designed and supervised the 2 research, analysed the data and wrote the manuscript, HL and JP designed and 3 carried out the experiments, collected and analysed the data and wrote the 4 manuscript, ZA performed platelet function assays and microfluidic studies, collected 5 and analysed the data, FR carried out histology and immunochemistry studies, 6 collected and analysed the data, JC provided conceptual input, designed experiments 7 and analysed data, ST and AA provide intellectual input, analysed clinical data and 8 managed VITT patients. All authors reviewed and edited the manuscript and approved 9 the final version of the manuscript.

10

11 Conflict of interest statement. The authors declare no conflicts of interest. 


\section{References}

1. Greinacher, A. et al. Thrombotic Thrombocytopenia after ChAdOx1 nCov-19 Vaccination. N Engl J Med 384, 2092-2101, (2021).

2. Scully, M. et al. Pathologic Antibodies to Platelet Factor 4 after ChAdOx1 nCoV-19 Vaccination. N Engl J Med 384, 2202-2211, (2021).

3. Pavord, S. et al. Clinical Features of Vaccine-Induced Immune Thrombocytopenia and Thrombosis. N. Engl. J. Med., (2021).

4. Cines, D. B. \& Bussel, J. B. SARS-CoV-2 Vaccine-Induced Immune Thrombotic Thrombocytopenia. N Engl J Med 384, 2254-2256, (2021).

5. Schultz, N. H. et al. Thrombosis and Thrombocytopenia after ChAdOx1 nCoV-19 Vaccination. N Engl J Med 384, 2124-2130, (2021).

6. Chong, B. H. Evolving concepts of pathogenesis of heparin-induced thrombocytopenia: Diagnostic and therapeutic implications. Int. J. Lab. Hematol. 42, 25-32, (2020).

7. Thiele, T. et al. Frequency of positive anti-PF4/polyanion antibody tests after COVID19 vaccination with ChAdOx1 nCoV-19 and BNT162b2. Blood 138, 299-303, (2021).

8. Leung, H. et al. Inhibition of NADPH oxidase blocks NETosis and reduces thrombosis in heparin-induced thrombocytopenia. Blood Advances, (2021).

9. Perdomo, J. et al. Neutrophil activation and NETosis are the major drivers of thrombosis in heparin-induced thrombocytopenia. Nat. Commun. 10, 1322, (2019).

10. Folco, E. J. et al. Neutrophil Extracellular Traps Induce Endothelial Cell Activation and Tissue Factor Production Through Interleukin-1 $\alpha$ and Cathepsin G. Arterioscler. Thromb. Vasc. Biol. 38, 1901-1912, (2018).

11. Thålin, C., Hisada, Y., Lundström, S., Mackman, N. \& Wallén, H. Neutrophil Extracellular Traps. Arterioscler. Thromb. Vasc. Biol. 39, 1724-1738, (2019).

12. Fuchs, T. A. et al. Extracellular DNA traps promote thrombosis. Proc. Natl. Acad. Sci. U. S. A. 107, 15880, (2010).

13. Laridan, E., Martinod, K. \& De Meyer, S. F. Neutrophil Extracellular Traps in Arterial and Venous Thrombosis. Semin. Thromb. Hemost. 45, 86-93, (2019).

14. Thålin, C. et al. Quantification of citrullinated histones: Development of an improved assay to reliably quantify nucleosomal H3Cit in human plasma. J. Thromb. Haemost. 18, 2732-2743, (2020).

15. Masuda, S. et al. NETosis markers: Quest for specific, objective, and quantitative markers. Clin. Chim. Acta 459, 89-93, (2016).

16. Nguyen, T.-H., Medvedev, N., Delcea, M. \& Greinacher, A. Anti-platelet factor $4 /$ polyanion antibodies mediate a new mechanism of autoimmunity. Nat. Commun. 8, 14945, (2017).

17. Lewis, H. D. et al. Inhibition of PAD4 activity is sufficient to disrupt mouse and human NET formation. Nat. Chem. Biol. 11, 189-191, (2015).

18. Thiam, H. R. et al. NETosis proceeds by cytoskeleton and endomembrane disassembly and PAD4-mediated chromatin decondensation and nuclear envelope rupture. Proc. Natl. Acad. Sci. U. S. A. 117, 7326, (2020).

19. Huynh, A., Kelton, J. G., Arnold, D. M., Daka, M. \& Nazy, I. Antibody epitopes in vaccine-induced immune thrombotic thrombocytopenia. Nature, (2021). 
20. Greinacher, A. et al. Anti-Platelet Factor 4 Antibodies Causing VITT do not CrossReact with SARS-CoV-2 Spike Protein. Blood, (2021).

21. Holm, S. et al. Immune complexes, innate immunity, and NETosis in ChAdOx1 vaccine-induced thrombocytopenia. Eur. Heart J., (2021).

22. Althaus, K. et al. Antibody-mediated procoagulant platelets in SARS-CoV-2vaccination associated immune thrombotic thrombocytopenia. Haematologica 106, 2170-2179, (2021).

23. Novotny, J. et al. Thrombus NET content is associated with clinical outcome in stroke and myocardial infarction. Neurology 94, e2346, (2020).

24. Chilingaryan, Z. et al. Erythrocyte interaction with neutrophil extracellular traps in coronary artery thrombosis following myocardial infarction. Pathology, (2021).

25. Brill, A. et al. Neutrophil extracellular traps promote deep vein thrombosis in mice. J. Thromb. Haemost. 10, 136-144, (2012).

26. Chong, B. H. \& Isaacs, A. Heparin-induced thrombocytopenia: What clinicians need to know. Thromb. Haemost. 101, 279-283, (2009).

27. Sheridan, D., Carter, C. \& Kelton, J. G. A diagnostic test for heparin-induced thrombocytopenia. Blood 67, 27-30, (1986).

28. Reilly, M. P. et al. Heparin-induced thrombocytopenia/thrombosis in a transgenic mouse model requires human platelet factor 4 and platelet activation through FcgammaRIIA. Blood 98, 2442-2447, (2001). 


\section{Platelet activation and NETosis in VITT}

a

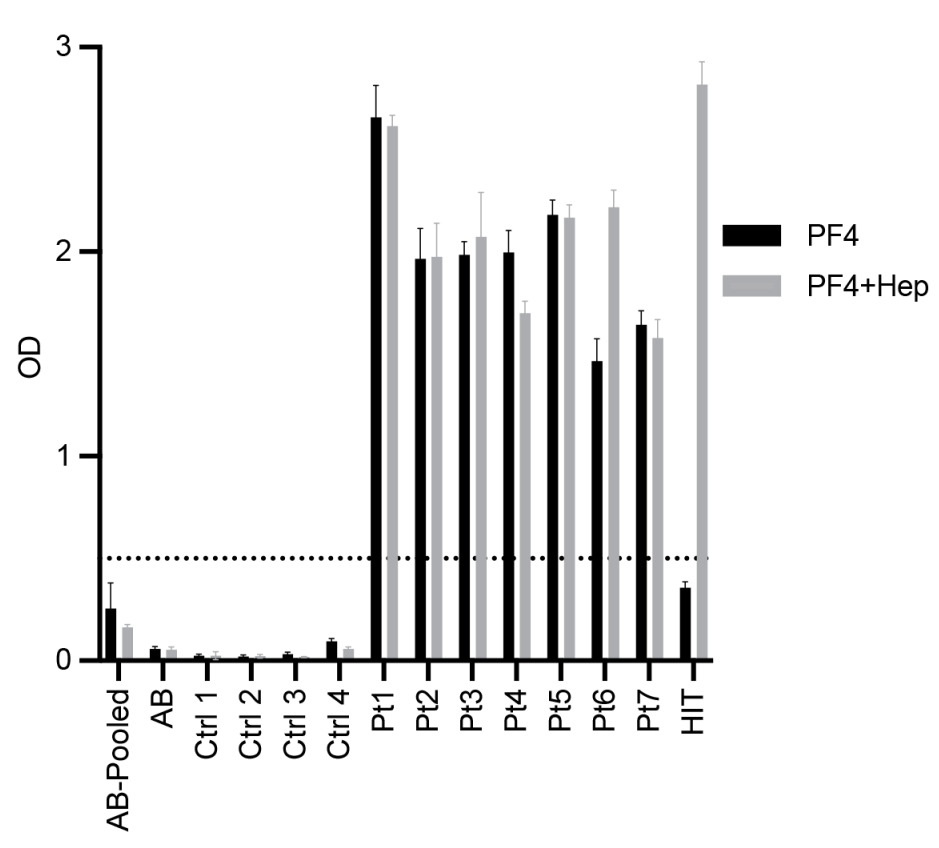

c

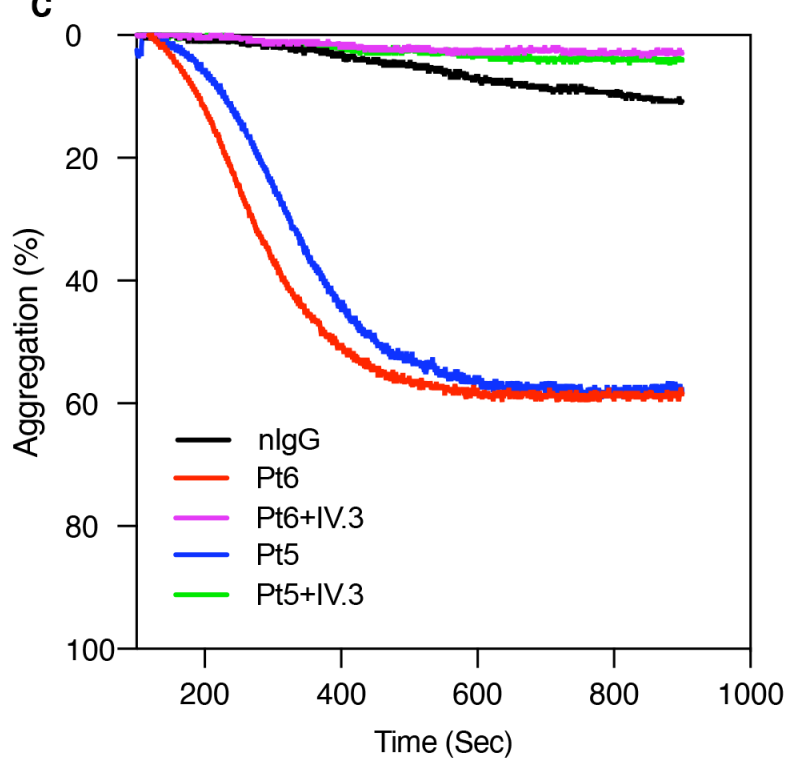

d b
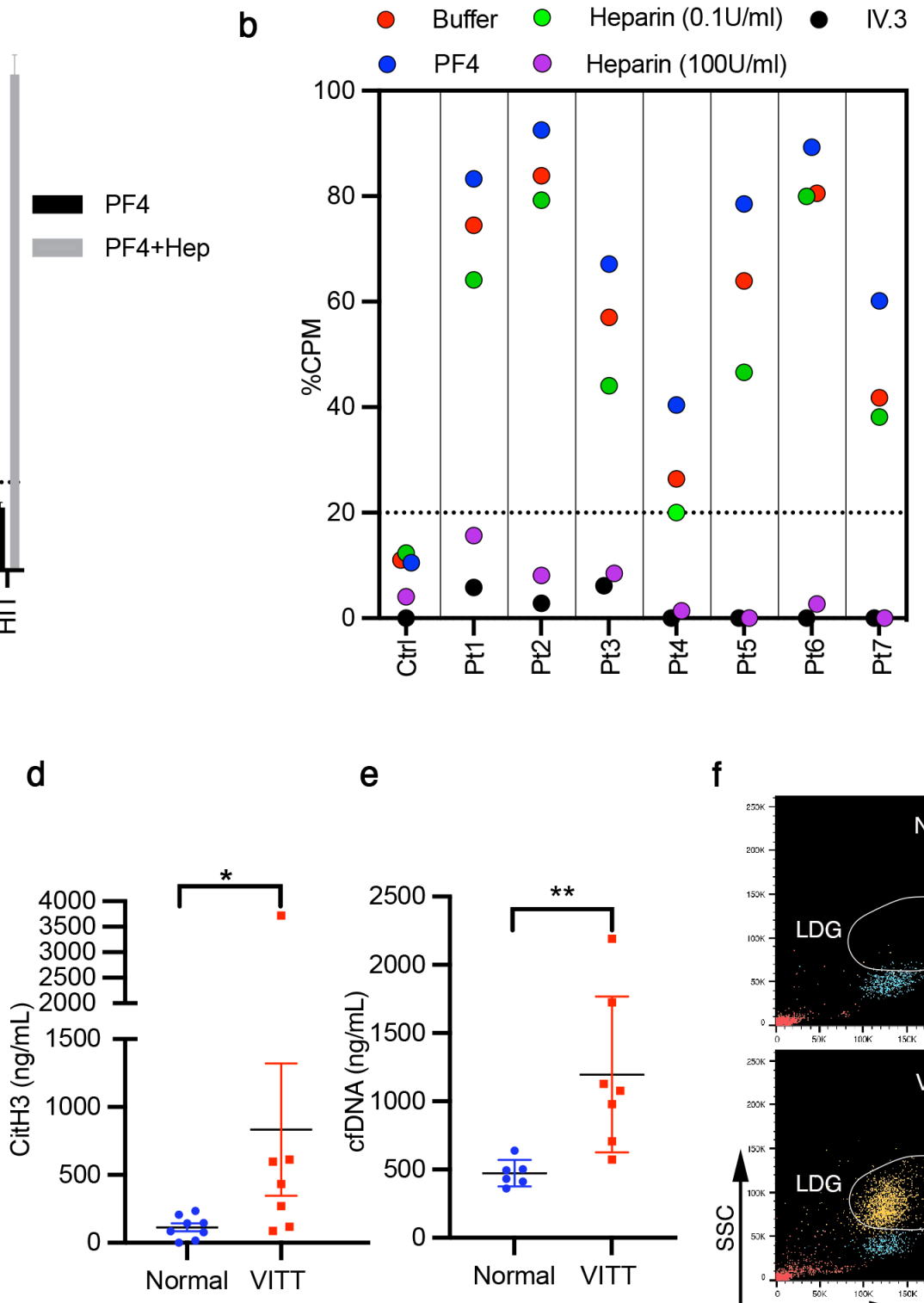

e

f

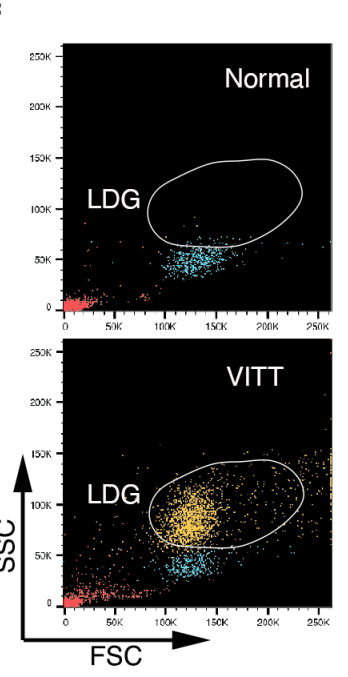

g

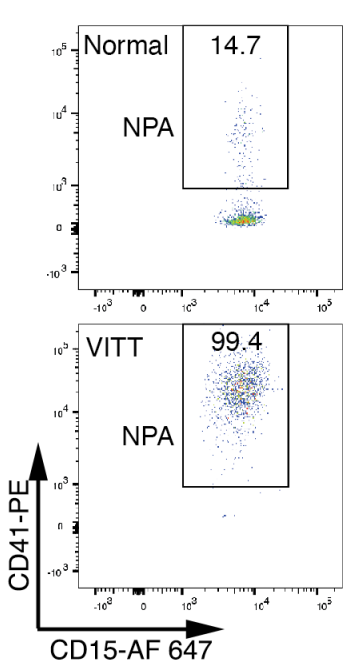

h

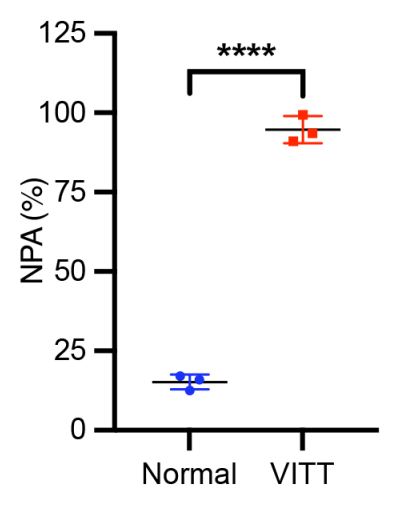

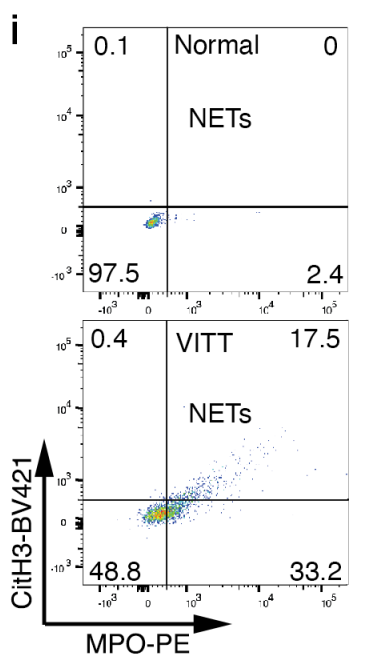

j

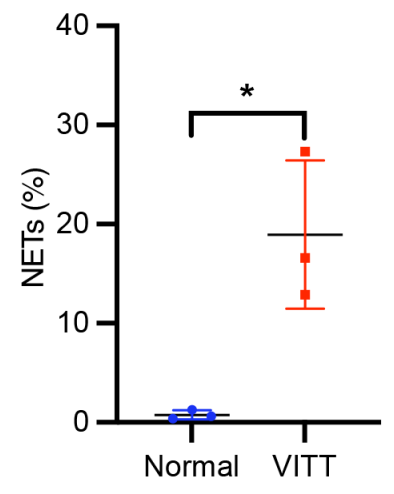


Figure 1. Platelet activation and NETosis in VITT. a PF4 and PF4-heparin ELISA experiment of VITT serum and normal controls. The cut-off, 0.50 OD units. b ${ }^{14} \mathrm{C}$ serotonin release assay for VITT samples with buffer alone, PF4 (10 $\mu \mathrm{g} / \mathrm{mL}), 0.1$ or $100 \mathrm{U} / \mathrm{mL}$ heparin or IV.3 antibody $(50 \mu \mathrm{g} / \mathrm{mL})$. Each dot represents the mean of assays done in triplicate. The cut-off was set at $20 \%$ CPM. c Platelet aggregation responses. Purified lgG from VITT patients induced aggregation in platelet rich plasma (red and blue traces). Blockage of Fc $\gamma$ RIla with IV.3 inhibited aggregation (purple and green traces). d Nucleosomal CitH3 levels in VITT patients' plasma $(n=7)$ relative to normal controls $(n=8)$ was determined by H3R8Cit ELISA. e cfDNA in VITT patients' plasma $(n=7)$ relative to normal controls $(n=6)$ determined by PicoGreen fluorescence assay. $\mathbf{f}$ Representative side and forward scatter flow cytometry plot backgated for neutrophils (yellow) and monocytes (blue) from VITT patient's and normal blood. LDG are indicated. $\mathbf{g}$ Representative plot of NPA from VITT and normal blood. $\mathbf{h}$ Quantification of NPA in VITT. i Representative plot of NETs from VITT and normal blood. $\mathbf{j}$ quantification of NETs in VITT. MPO ${ }^{+} \mathrm{CitH}^{+}$double positive cells within the $\mathrm{CD}_{15}{ }^{+}$population were defined as neutrophils undergoing NETosis. The percentage of gated events is indicated in each quadrant. Statistics, Mann-Whitney test. ${ }^{*} \mathrm{P}<$ $0.05 ;{ }^{* *} \mathrm{P}<0.01 ;{ }^{* * *} \mathrm{P}<0.0001$. OD, optical density units; CPM, counts per minute; NPA, neutrophil-platelet aggregates; LDG, low density granulocytes; cfDNA, cell-free DNA; CitH3, citrullinated histone $\mathrm{H3}$; $\mathrm{Pt}$, patient. 


\section{Effect of VITT IgG on donor's blood}
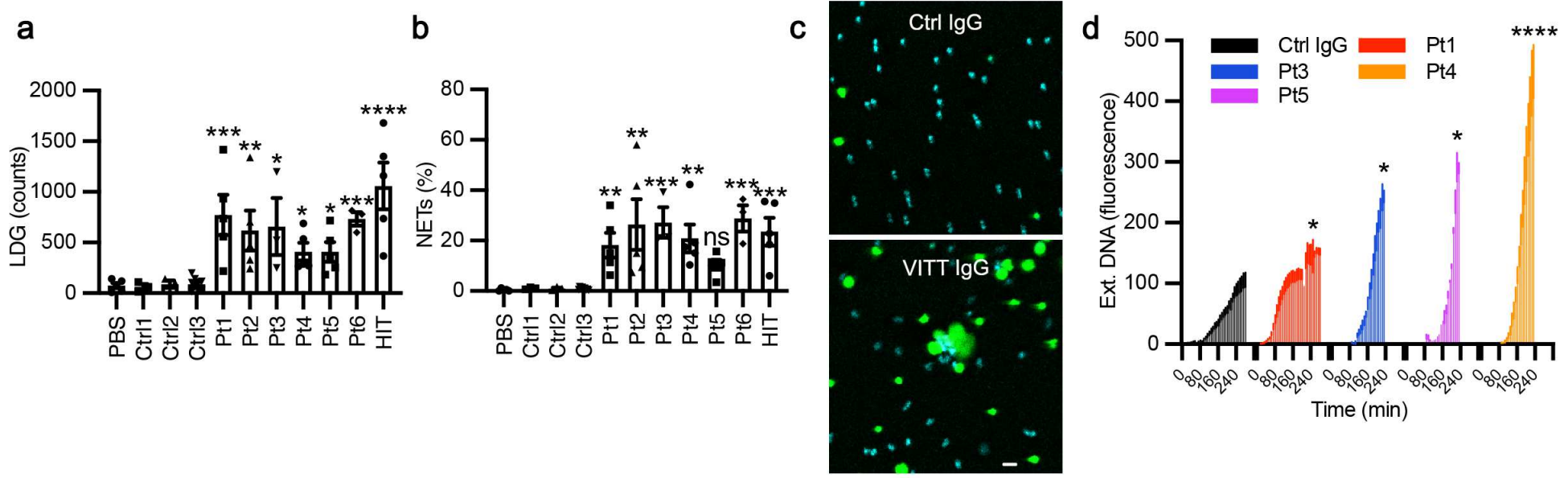

e
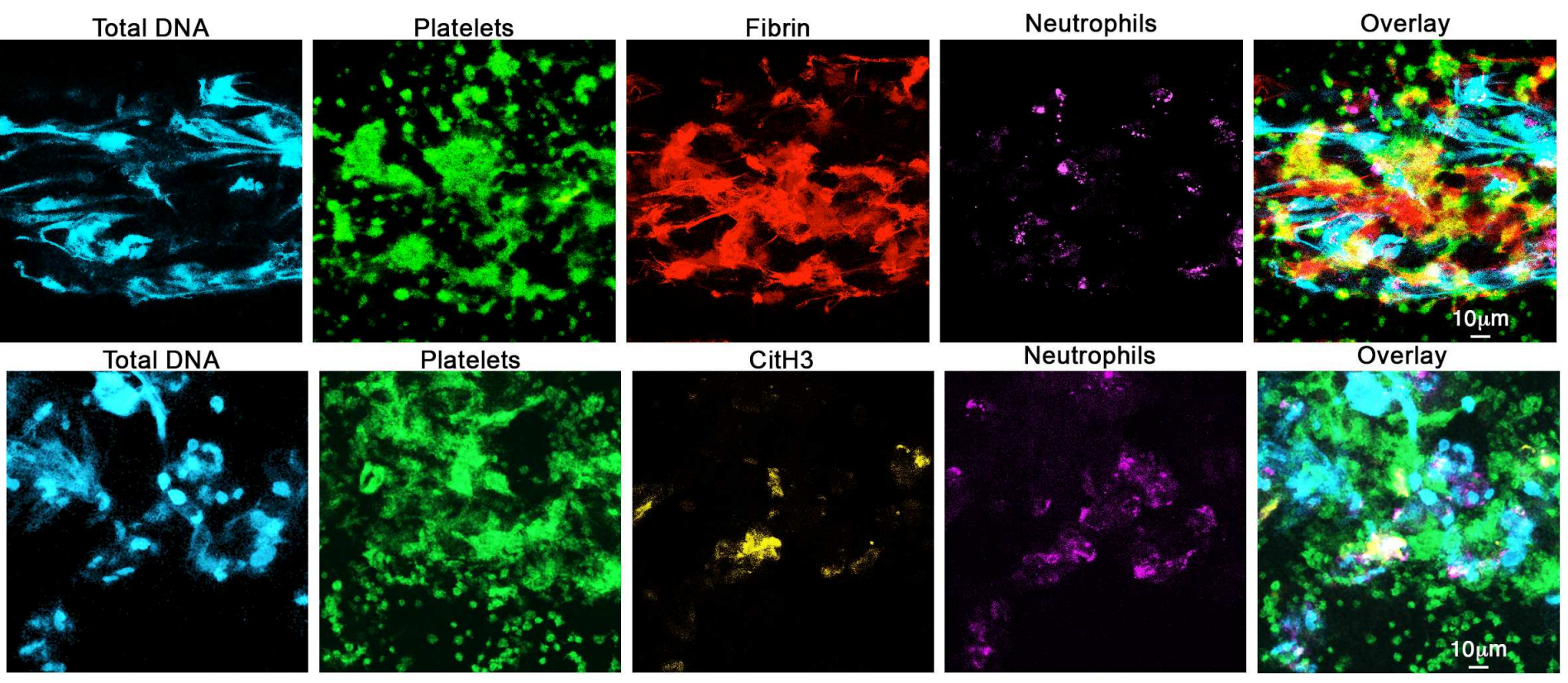

g

Total DNA

Platelets

Neutrophils

Overlay
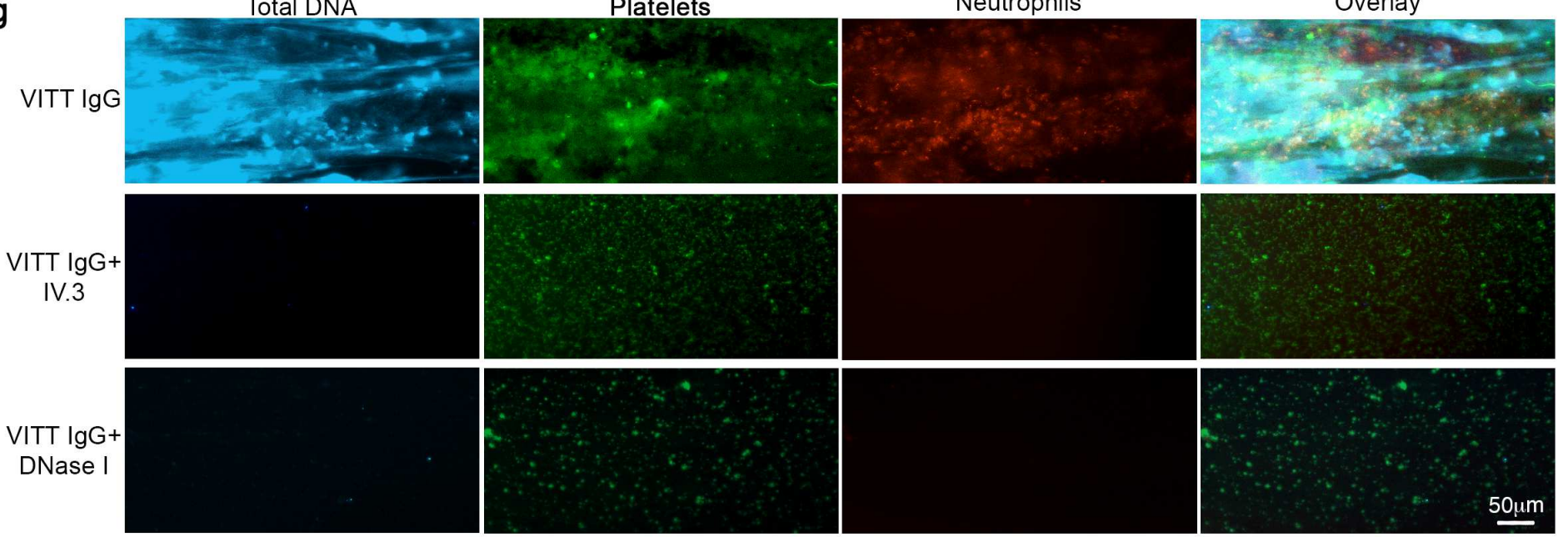

$50 \mu \mathrm{m}$
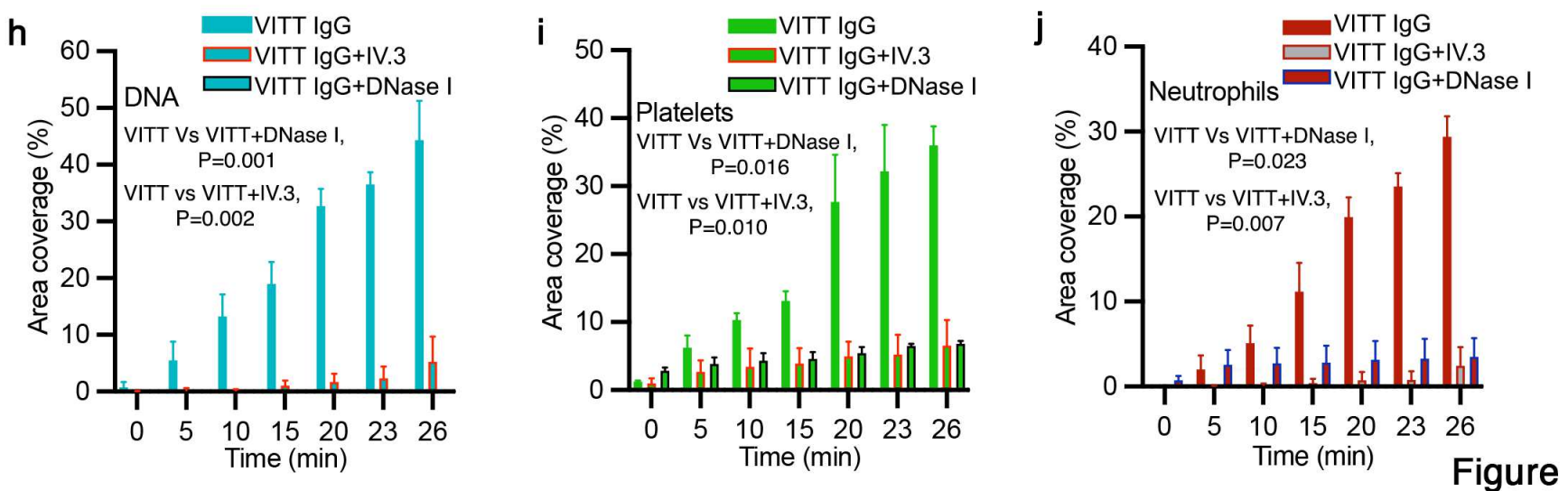

Figure 2 
Figure 2. Effect of VITT IgG on donor's blood. a Quantification of LDG and $\mathbf{b}$ NETs following treatment of healthy donor blood with VITT, normal controls and HIT IgG. C Purified neutrophils treated with VITT IgG or normal IgG plus PF4 were stained for extracellular DNA (green) and nuclei (blue). d DNA release calculated as fluorescence intensity ratio of extracellular DNA (Sytox staining)/total DNA (Hoechst staining) vs. time $(n=3)$. e VITT IgG induces thrombosis. Healthy donors' blood treated with VITT IgG was stained for total DNA (blue), platelets (green), fibrin (red) and neutrophils (magenta). Thrombi were imaged with a confocal laser-scanning microscope (overlap of green and red shown as yellow). Scale bar: $10 \mu \mathrm{m}$. f Thrombi contain CitH3. Thrombi were generated and imaged as in (e), and stained for DNA (blue), platelets (green), CitH3 (yellow) and neutrophils (magenta). Overlap of yellow and green is shown as white. $\mathbf{g}$ IV.3 and DNase I prevent VITT IgG-induced thrombus formation in microfluidics system. Treated blood was stained for DNA (blue), platelets (green) and neutrophils (red). Scale bar: $50 \mu \mathrm{m}$. Graphs show area coverage percentage for $\mathbf{h}$ total DNA, i platelets and $\mathbf{j}$ neutrophils. $n=3$, mean \pm s.d. Statistics: $(\mathbf{a}, \mathbf{b})$ Kruskal-Wallis test with uncorrected Dunn's test, (d) One-way ANOVA followed by Dunn's test for multiple comparisons, (h, i, j) One-way ANOVA with Tukey's correction for multiple comparisons. ${ }^{*} P<0.05 ;{ }^{* *} P<0.01 ;{ }^{* *} P<0.001$, ${ }^{* * *} P<0.0001$. LDG, low density granulocytes; ext. DNA, extracellular DNA; Ctrl, control; Pt, patient. 


\section{VITT IgG induces thrombosis in FcyRlla $/ \mathrm{hPF}^{+}$mice}

\section{nlgG}

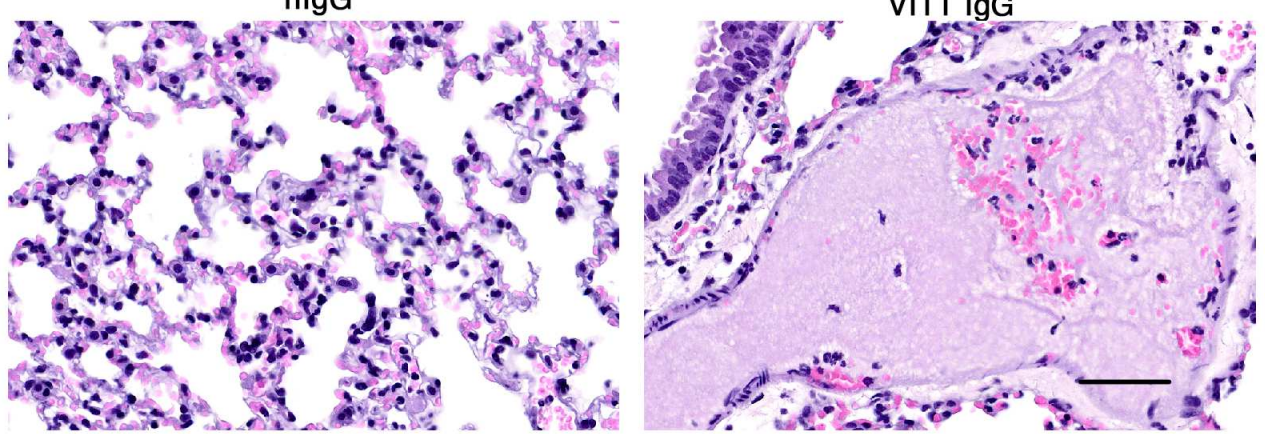

b

DAPI/Neutrophils/Platelets

DAPI/Neutrophils/Platelets

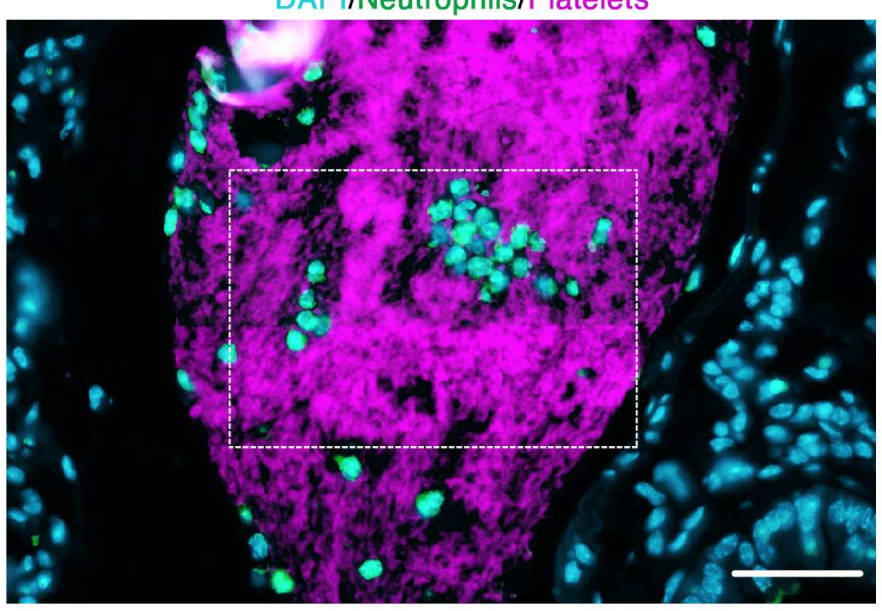

C

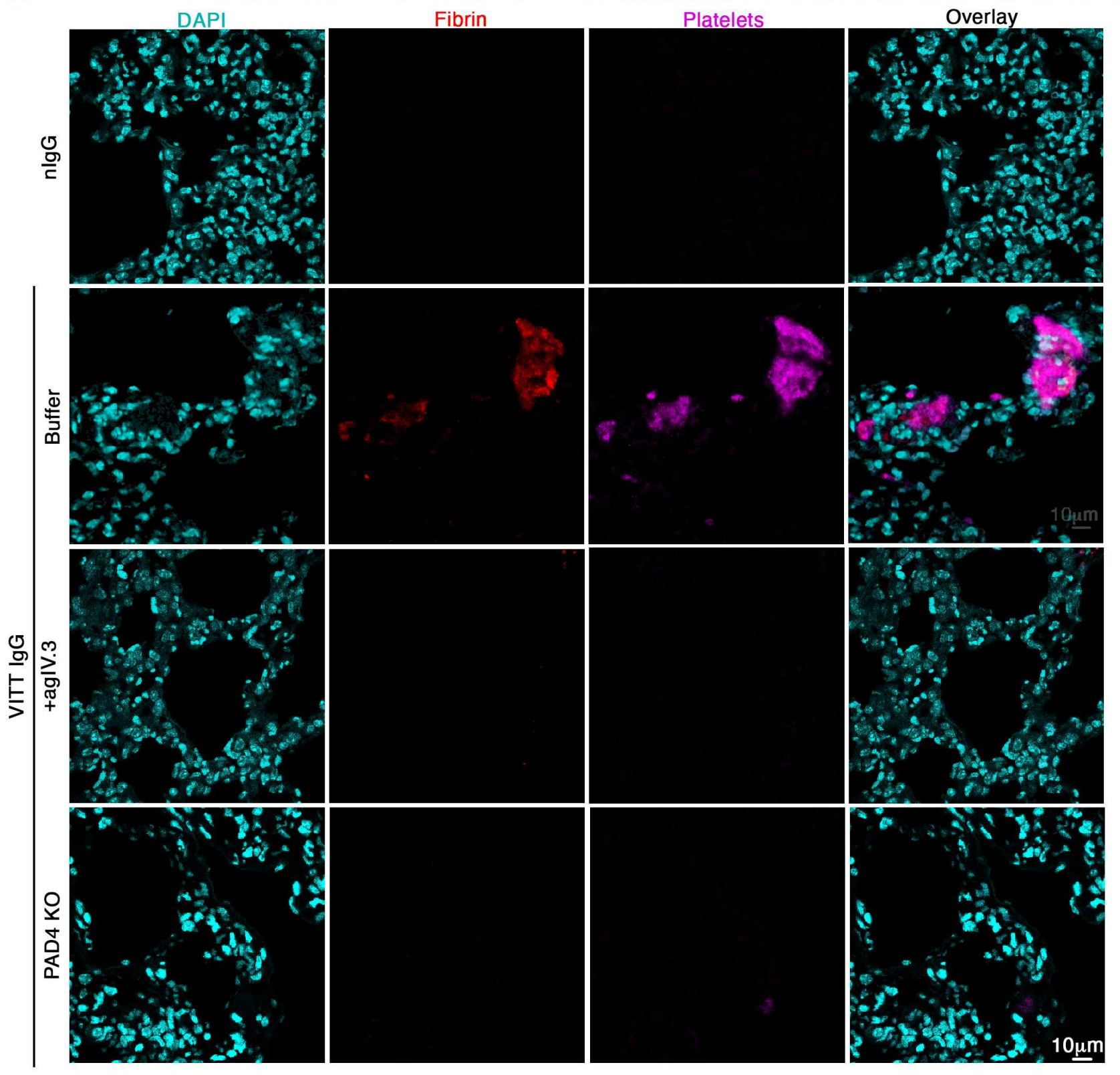


Figure 3. VITT IgG induces thrombosis in $\mathrm{FcyRlla}^{+} / \mathrm{hPF} 4^{+}$mice. a Representative $\mathrm{H} \& \mathrm{E}$ staining of lung sections of mice treated with nlgG or VITT IgG. Scale bar $50 \mu \mathrm{m}$. b Fluorescent images of lung sections of mice treated with VITT IgG. Platelets were labelled in vivo with anti-CD42c-Dylight 649 (magenta). Neutrophil were stained with anti-Ly6G (green). Neutrophil infiltration in the clot is shown. Cell nuclei were stained with DAPI (blue). Scale bars $50 \mu \mathrm{m}$. c Fluorescent images of lung sections of $\mathrm{FcyRlla}^{+} / \mathrm{hPF}^{+}$mice treated with $\mathrm{nlgG}$, VITT IgG or VITT IgG plus agIV. 3 or $\mathrm{FcyRlla}^{+} / \mathrm{hPF}^{+} / \mathrm{PAD}^{-/-}$mice treated with VITT IgG. Fibrin labelled with AF594 (red) resulted from injection of AF594-labelled fibrinogen at $1 \mu \mathrm{g} / \mathrm{g}$. Platelets were labelled in vivo with anti-CD42c-Dylight 649 (magenta). Cell nuclei were stained with DAPI (blue). Scale bar $10 \mu \mathrm{m}$. nlgG, normal IgG; agIV.3, aglycosylated IV.3 antibody. 


\section{Thrombosis and thrombocytopenia}

a

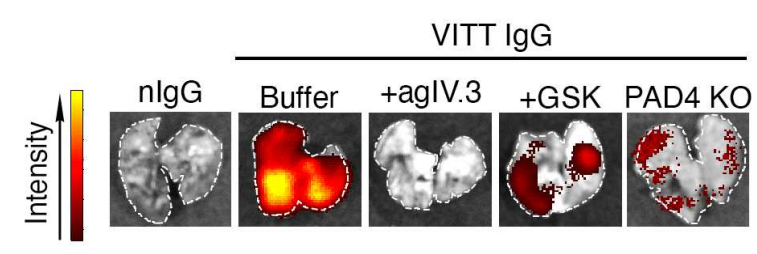

b

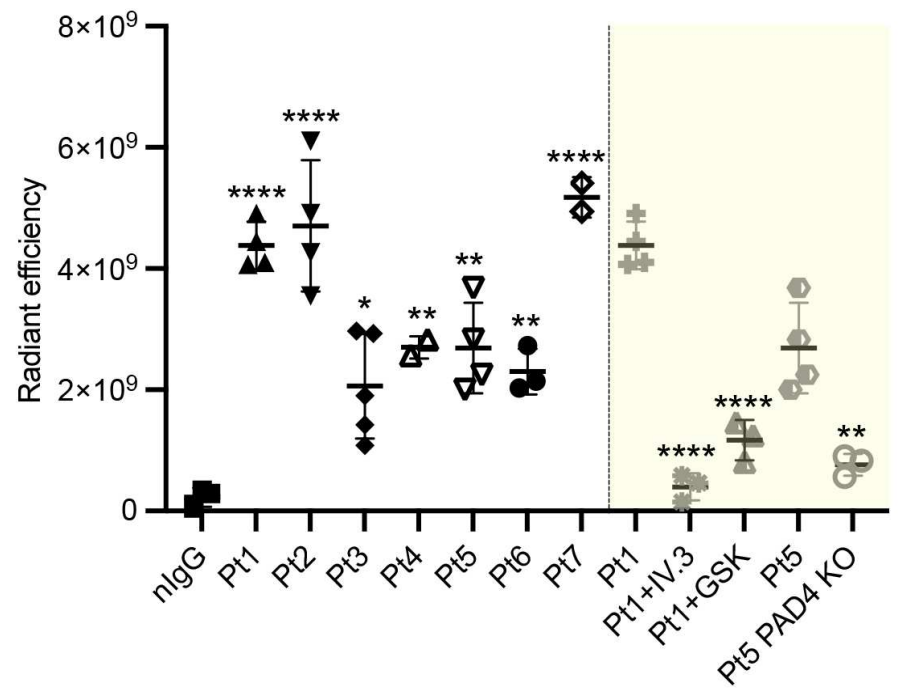

C

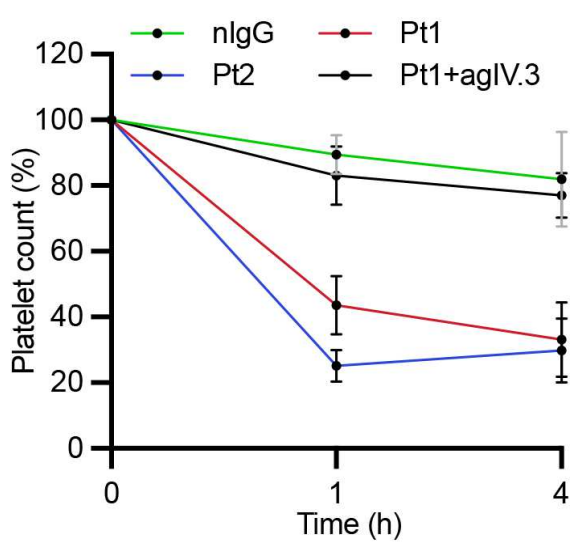

e

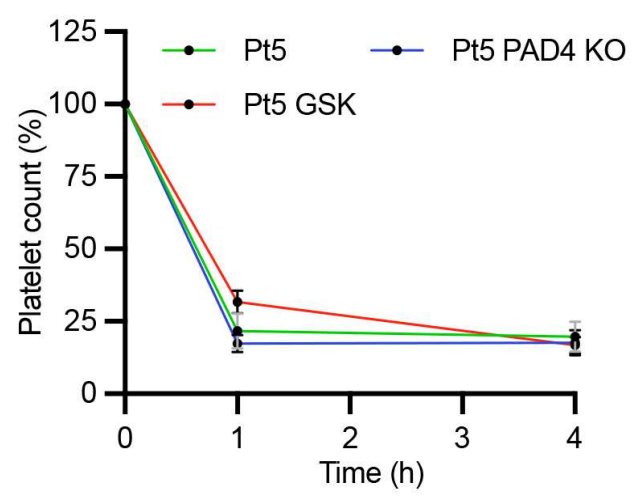

d

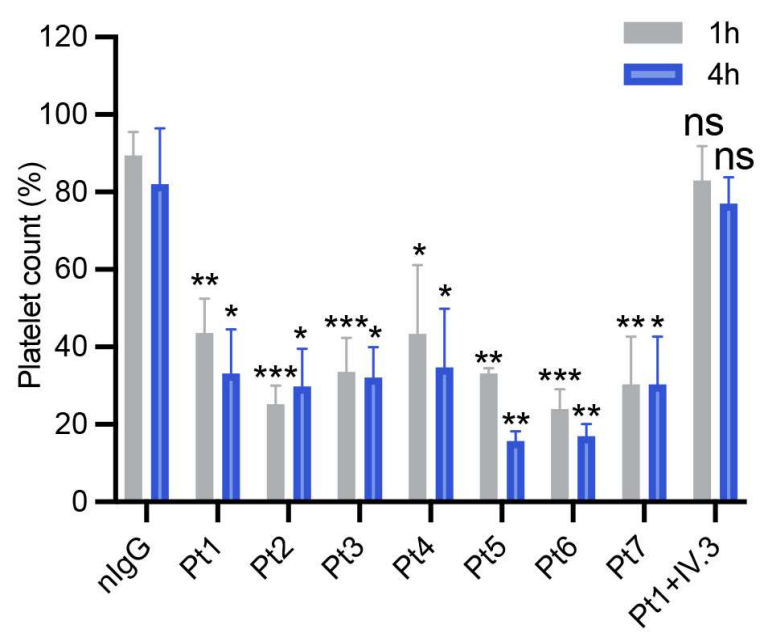


Figure 4. Thrombosis and thrombocytopenia. a Representative images of lungs following treatment. The level of fluorescence indicates accumulation of platelets labelled with anti-CD42c-Dylight 649 in the lungs. b Graph of lung fluorescence for the VITT patients indicated. c Representative graph showing platelet counts following treatment of $\mathrm{FcyRlla}^{+} / \mathrm{hPF}^{+}$mice with normal $\mathrm{lgG}$ (nlgG) or VITT IgG or VITT IgG plus agIV. 3 determined at $1 \mathrm{~h}$ and $4 \mathrm{~h}$ after treatment. $\mathbf{d}$ Quantification of platelet counts in $\mathrm{FcyRIla}^{+} / \mathrm{hPF} 4^{+}$mice following the treatments indicated in the figure. e Graph showing platelet counts following treatment of $\mathrm{FcyRIla}+/ \mathrm{hPF}^{+}$mice with $\mathrm{VITT}$ IgG with or without GSK or $\mathrm{FcyRIIa}^{+} / \mathrm{hPF}^{+} / \mathrm{PAD} 4^{-/-}$mice plus VITT IgG determined at $1 \mathrm{~h}$ and $4 \mathrm{~h}$ after treatment. Statistics. b One-way ANOVA with Dunnet's test for multiple comparisons. Unpaired t test for comparison between Pt5 in FcyRlla ${ }^{+} / \mathrm{hPF}^{+}$and Pt 5 in FcyRlla ${ }^{+} / \mathrm{hPF}^{+} / \mathrm{PAD} 4^{-/}$mice. d One-way ANOVA with Dunnet's test for multiple comparisons. nlgG, normal IgG; PAD4 KO, PAD4 knockout FcyRlla ${ }^{+} / \mathrm{hPF}^{+}$mice; agIV.3, aglycosylated IV.3 antibody; Pt, patient. 
Thrombosis in vitro and in vivo

a

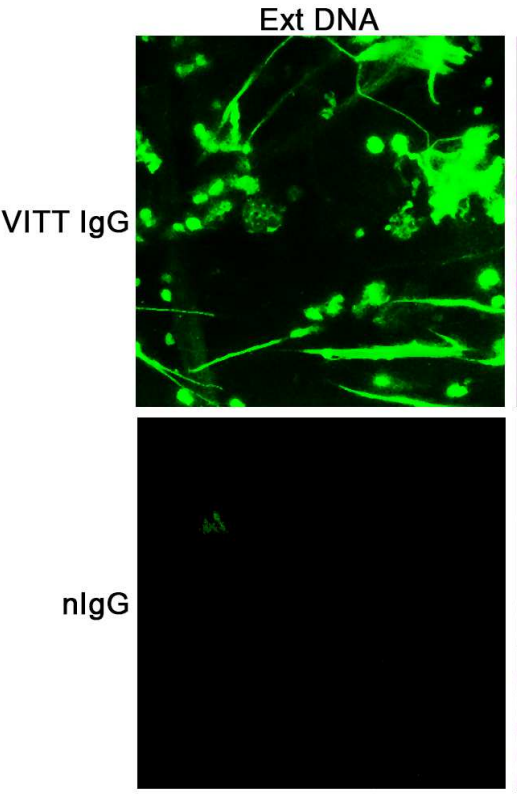

Platelets

Neutrophils

Overlay
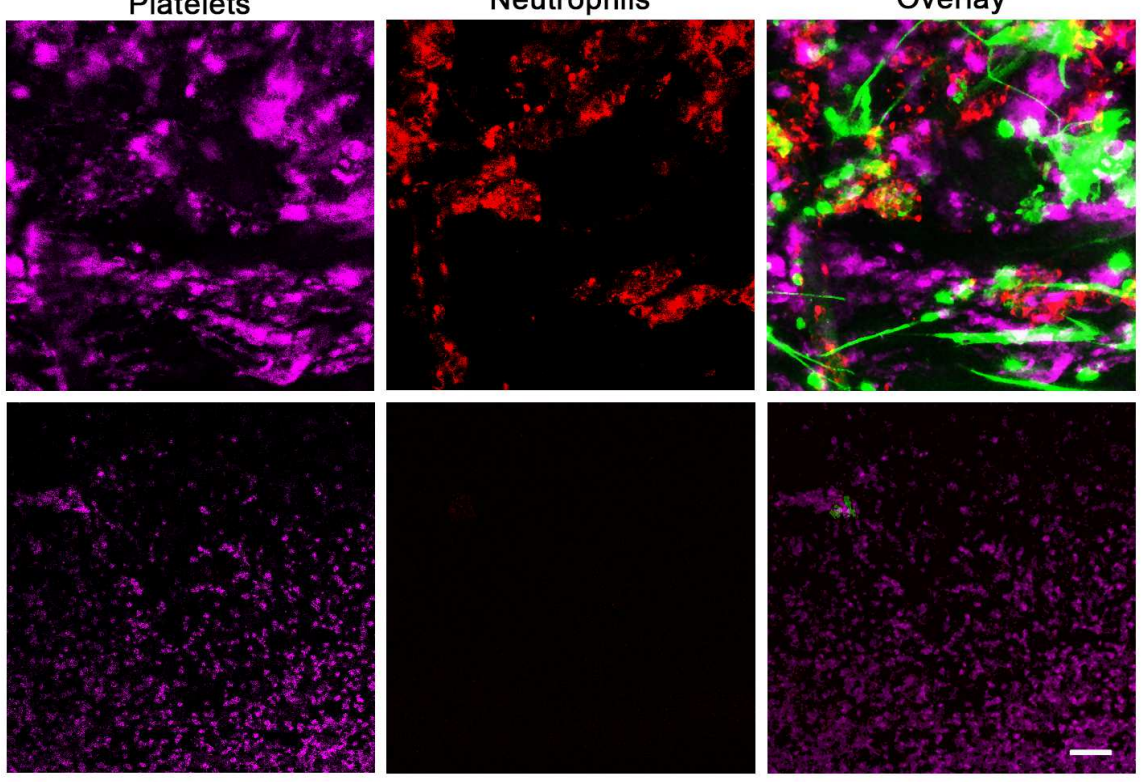

b

Total DNA

Platelets

Neutrophils

Overlay
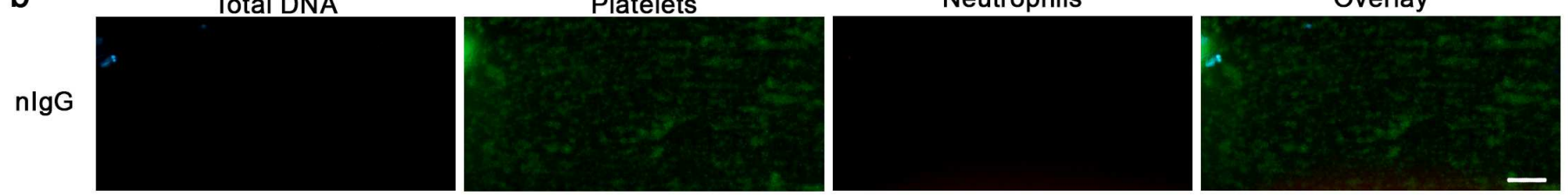

$\mathrm{FcgRIla}^{+} / \mathrm{hPF}^{+}$

C
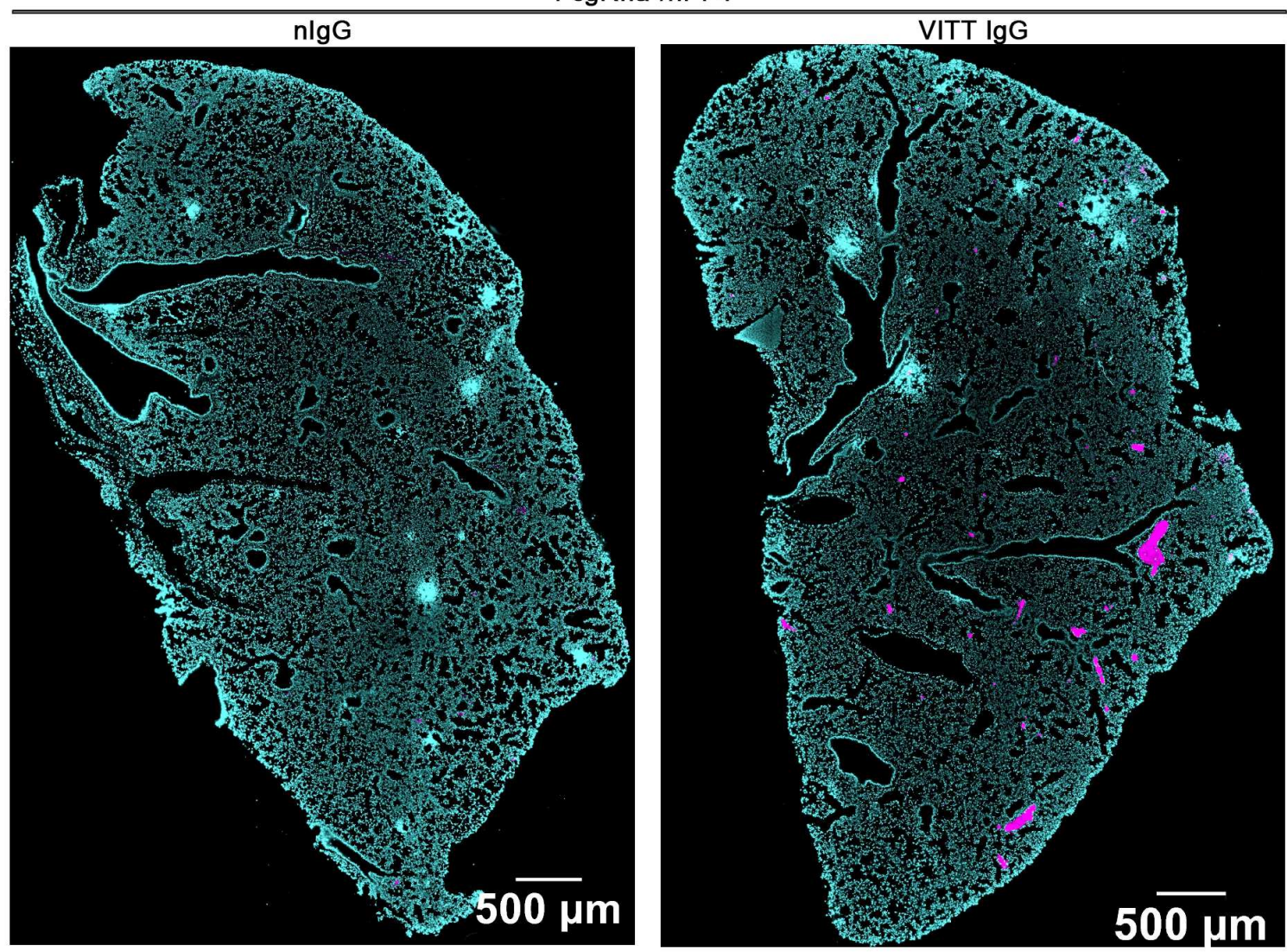

d

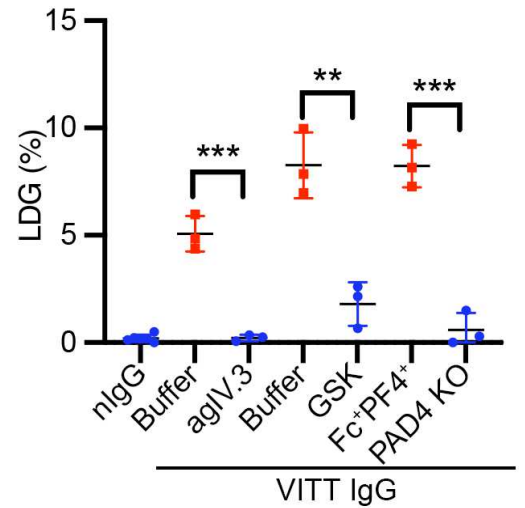


Extended Data Figure 1. a VITT IgG and thrombosis. Healthy donors' blood treated with VITT IgG was flowed in vWf-coated microchannels. Extracellular DNA was stained with Sytox green (green), platelets with anti-CD41 AF647 (magenta) and neutrophils with anti-CD15 AF594 (red). Thrombi were imaged with a confocal laserscanning microscope (Leica TCS SP8 running Leica's LAS X software) with a $63 x$ oil immersion objective. Scale bar $20 \mu \mathrm{m}$. b Healthy donors' blood treated with normal IgG was flowed in vWf-coated microchannels. Total DNA was stained with Hoechst 33342 (blue), platelets with anti-CD41-FITC (green) and neutrophils with anti-CD15 AF594 (red). Scale bar $50 \mu \mathrm{m}$. c Fluorescent images of lung lobes from mice treated with VITT IgG or control IgG. DAPI-stained nuclei (blue), platelet-rich thrombi (magenta). Scale bar $500 \mu \mathrm{m}$. d Level of low density granulocytes (LDG) in blood from mice following the treatments indicated in the Figure. Statistics: Unpaired $t$ test. nlgG, normal IgG; PAD4 KO, PAD4 knockout FcyRlla $/ \mathrm{hPF}^{+}$mice. 
Systemic response and proposed mechanism of thrombocytopenia and thrombosis in VITT

a

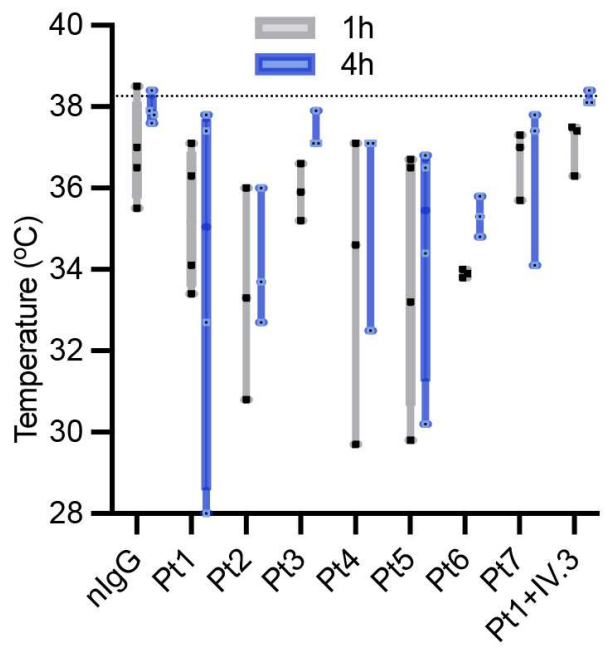

b
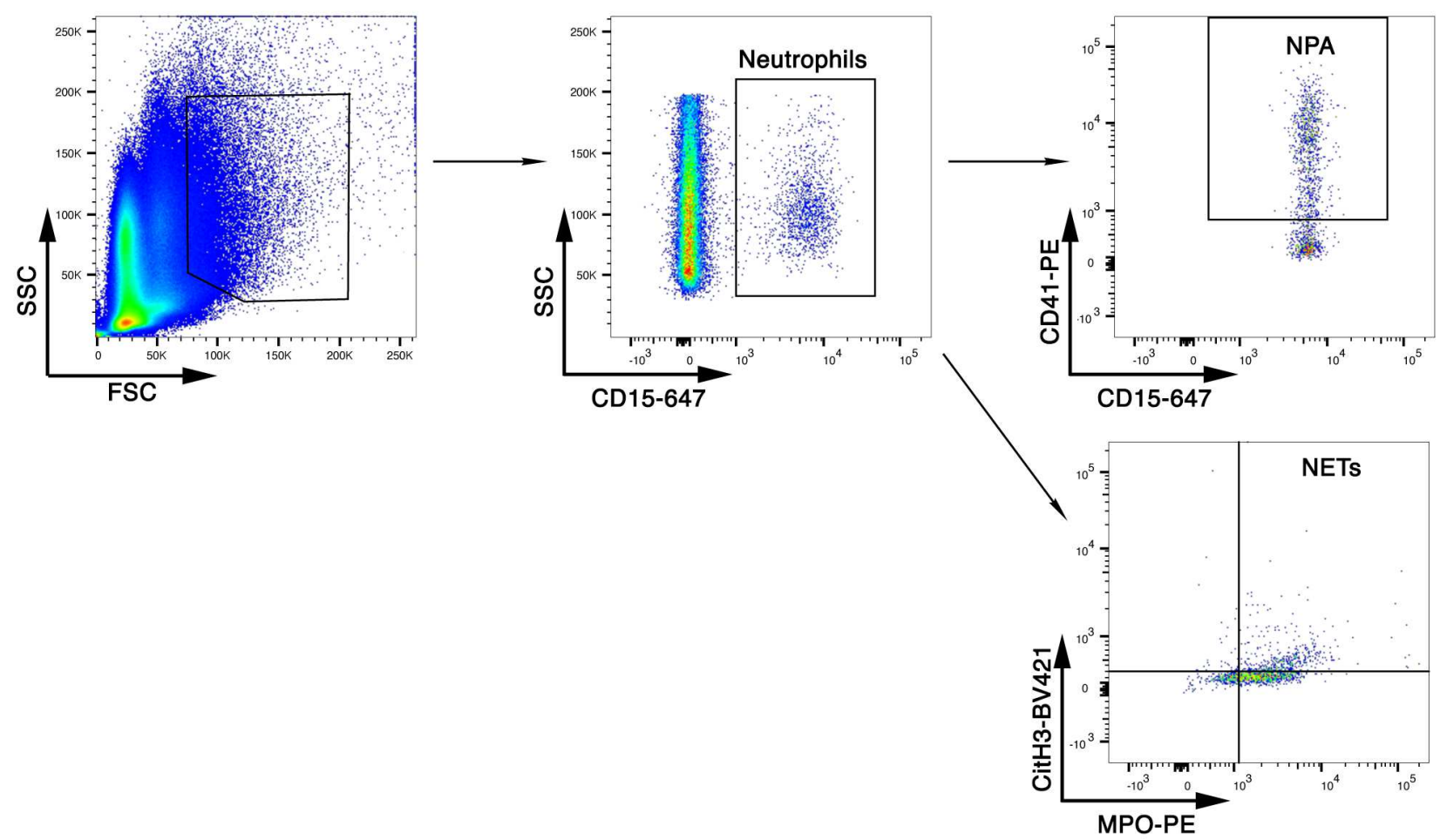

C
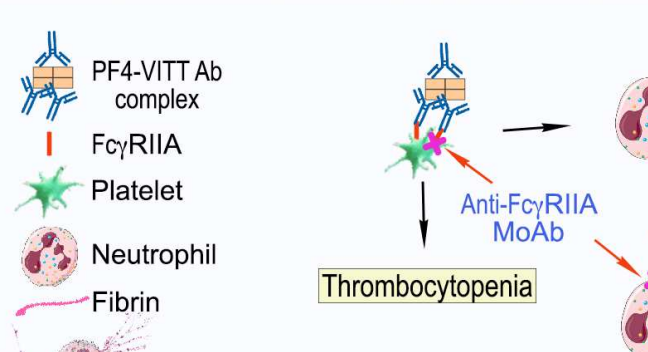

Activated neutrophil and NETs release 
Extended Data Figure 2. a Changes in temperature following the treatments indicated in the figure. Dotted line represents the mean temperature of mice before treatment $\left(38.3^{\circ} \mathrm{C}, \mathrm{n}=30\right)$. $\mathbf{b}$ Model of mechanism of thrombosis and thrombocytopenia in VITT. Anti-PF4 antibodies from VITT patients form a complex with PF4 and interact with FcyRlla. Interaction of the complex with platelets results in thrombocytopenia, which can be blocked with the monoclonal antibody IV.3. In the case of neutrophils, the interaction of the complex with FcyRlla leads to NETs formation and subsequent thrombosis. Thrombosis can be blocked by neutralisation of FcyRlla with IV.3 or by inhibition of NETosis using NETs inhibitor or in PAD4 knockout mice. In vitro, addition of DNase I disrupts thrombus formation. 